\title{
Understanding hereditary diseases using the dog and human as companion model systems
}

\author{
Kate L. Tsai · Leigh Anne Clark · Keith E. Murphy
}

Received: 9 March 2007 / Accepted: 15 May 2007/Published online: 26 July 2007

(C) Springer Science+Business Media, LLC 2007

\begin{abstract}
Animal models are requisite for genetic dissection of, and improved treatment regimens for, human hereditary diseases. While several animals have been used in academic and industrial research, the primary model for dissection of hereditary diseases has been the many strains of the laboratory mouse. However, given its greater (than the mouse) genetic similarity to the human, high number of naturally occurring hereditary diseases, unique population structure, and the availability of the complete genome sequence, the purebred dog has emerged as a powerful model for study of diseases. The major advantage the dog provides is that it is afflicted with approximately 450 hereditary diseases, about half of which have remarkable clinical similarities to corresponding diseases of the human. In addition, humankind has a strong desire to cure diseases of the dog so these two facts make the dog an ideal clinical and genetic model. This review highlights several of these shared hereditary diseases. Specifically, the canine models discussed herein have played important roles in identification of causative genes and/or have been utilized in novel therapeutic approaches of interest to the dog and human.
\end{abstract}

\section{Introduction}

Model systems are vital for the study of disease and the development of new therapeutic approaches. The dog was

K. L. Tsai · L. A. Clark · K. E. Murphy $(\bowtie)$ Department of Pathobiology, College of Veterinary Medicine and Biomedical Sciences, Texas A\&M University, College Station, Texas 77843-4467, USA

e-mail: kmurphy@cvm.tamu.edu not immediately recognized as a model for hereditary diseases and few genetic-oriented investigations were carried out until the mid-1990s. Since that time, the canine genetics research community has made significant strides, producing dense linkage and radiation hybrid maps, oligobased microarrays, SNP arrays, and, most importantly, the sequence of the canine genome at 7.6X coverage (Breen et al. 2004; Clark et al. 2005; Guyon et al. 2003; LinbladToh 2006; Linblad-Toh et al. 2005).

The dog offers many of the same advantages of other small animal models. For example, homogeneous populations exist in each of the hundreds of pure breeds, and pedigrees can be easily established in rapid fashion. One advantage that other model systems do not have is that for the dog, pet populations can often be utilized, thereby often eliminating the need for establishment of colonies. Dogs possess other characteristics that are not found in traditional rodent models in that they (1) receive exceptional medical care, (2) have comparable organ sizes (to humans), and (3) generally cohabitate with their human owners, minimizing different environmental effects (Ostrander et al. 2000). The last issue is of particular interest. Specifically, because the dog does live with us, it is exposed to the same environment. Of course, the dog may react differently to such influences/stress than does the human, but living in the same environment is more advantageous when compared to environments in which classic laboratory research animals are maintained because those environments are far different from the ones inhabited by humans. Thus, when modeling the causes and pathogenesis of human hereditary diseases, any environment-gene interactions are likely better studied in an animal that lives in the same environment.

Perhaps the most exciting feature of the canine model is that 220 naturally occurring disease phenotypes are potential models for various human hereditary diseases 
(Online Mendelian Inheritance in Animals 2007; http:// www.omia.angis.org.au).

While the mouse is indisputably a fundamental resource for the study of human hereditary diseases, the canine model offers the opportunity to gain knowledge in areas for which the mouse is deficient. For example, genetically altered mice are not available for every disease of interest and alternative models must be identified in these instances. There are more than 450 canine hereditary diseases that provide naturally occurring models in which to study diseases (Ostrander and Giniger 1997). Among these are diseases transmitted in X-linked, autosomal recessive, and autosomal dominant fashions. Also, there are diseases for which canine models were identified before the development of murine models and were used to investigate pathogenesis and treatment regimens. An example of this is hereditary nephropathy (Kashtan 2002).

Research pertaining to spontaneous phenotypes of the dog has revealed genes and pathways novel to diseases. A prime example of this is the work on narcolepsy. In the 1990s, identification of the genetic basis of narcolepsy in the dog led investigators to a pathway not previously known to be involved in the disorder (Lin et al. 1999). Another example is the recent identification of a novel gene that causes retinal degeneration in the dog. It was subsequently determined that an identical mutation in the homologous gene was also responsible for a similar phenotype in a human patient (Zangerl et al. 2006b). While these are hallmark examples of the utility of the canine system, its full potential has yet to be realized because, to date, only a fraction of all hereditary traits have been characterized at the molecular level (http://www.omia.angis.org.au).

Phenotypes resulting from induced models of disease are not always clinically equivalent to those observed in humans. For example, a dystrophin knockout mouse with muscular dystrophy shows muscular weakness but not the continued wasting that is found in human patients (Tanabe et al. 1986). Such incongruities may diminish the usefulness of the model, specifically with regard to testing of possible treatments. In the last decade spontaneous canine models have been instrumental in the development of molecular therapies for human disease; e.g., data obtained from a canine model of hemophilia B led to clinical trials in humans (High 2004). Presented here is a review of the aforementioned diseases for which examination of canine models has revealed previously unknown genetic bases and/or facilitated development of novel treatment options.

\section{Hereditary nephropathy and Alport syndrome}

Hereditary nephropathy $(\mathrm{HN})$ is a broad term for certain fatal inherited diseases that result in renal failure. Alport syndrome (AS) is a form of HN in humans caused by defects in the glomerular basement membrane (GBM) (Kashtan 1998; Tryggvason and Martin 2001). The only treatments currently available for AS are dialysis and renal transplant. Mutations in the type IV collagen genes cause AS, which is primarily inherited in X-linked (XLAS) and autosomal recessive (ARAS) fashions. There is also a rare autosomal dominant (ADAS) form (Hudson et al. 2003). XLAS results from mutations in COLAA5 and accounts for $85 \%$ of cases, while ARAS and ADAS are caused by mutations in COLAA3 or COLAA4 (Jais et al. 2000; Knebelmann et al. 1995; Lemmink et al. 1994; Martin et al. 1998; Mochizuki et al. 1994). Mutations in any of these genes alter the triple helix formed by the COL4A3, COL4A4, and COL4A5 proteins that are necessary for proper GBM formation in the kidney.

Murine models for AS did not exist until 1996 when two transgenic models for ARAS were developed and characterized (Cosgrove et al. 1996; Miner and Sanes 1996). A murine model for XLAS was not described until 2004, despite it being the most common genetic form of AS (Rheault et al. 2004). To date, a murine model for ADAS has not been developed. Naturally occurring HN has been identified in several canine families. The progression of the disease is very similar to AS in humans with the exception of auditory and ophthalmologic abnormalities, which have not been described in the dog. X-linked HN (XLHN) in the dog was identified first in the Samoyed and later in a mixed-breed family (Fig. 1) (Jansen et al. 1986; Lees et al. 1999). A single-base substitution in exon 35 in the Samoyed and a 10-bp deletion in exon 9 in the mixed-breed dog result in premature stop codons and truncated COL4A5 proteins (Cox et al. 2003; Zheng et al. 1994). The English cocker spaniel presents with a renal disease (termed ARHN) similar to ARAS that is caused by a nonsense mutation in exon 3 of COLAA4 (Davidson et al. 2007). The bull terrier is affected by ADHN but the mutation has not been characterized (Hood et al. 1995).

Because dialysis and renal transplants are the only treatments available for AS, correction of the defective GBM via gene therapy as a possible remedy is being explored. In an initial experiment, an adenoviral vector containing a human cDNA construct of COLAA5 was successfully expressed in the kidney of normal pigs (Heikkilä et al. 2001). This study proved that the construct could produce a functional protein capable of trimerizing with COL4A3 and COL4A4 (Heikkilä et al. 2001). To assess the functionality of this in a diseased system, a canine cDNA construct was designed for use in a canine model of the disease (Harvey et al. 2003). Because vector delivery methods are complicated in the kidney, studies were carried out in the bladder. In the smooth muscle of the bladder, COL4A5 and COL4A6 form a trimer composed of 

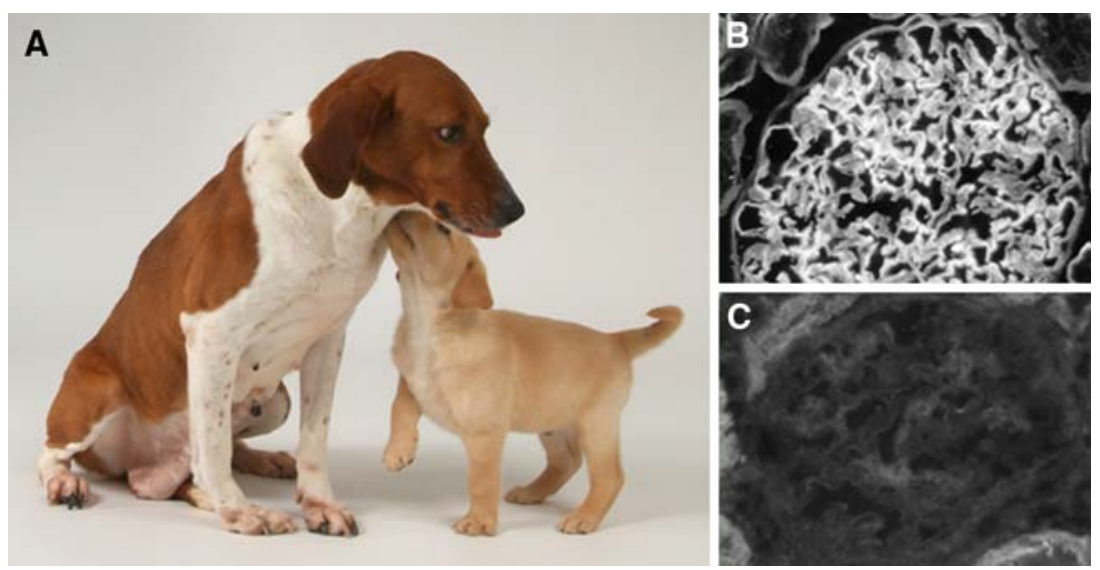

Fig. 1 A Hound/Labrador retriever colony having XLHN is maintained at Texas A\&M University. A A carrier female (left) can live up to seven years. An affected male (right) will enter renal failure before two years of age. B Immunofluorescent staining for COL4A5 in glomeruli of a normal dog. C Immunofluorescent staining for COL4A5 in glomeruli of an affected dog showing complete lack of labeling. Glomeruli images taken with permission from Am J Vet Res (1999) 60(3):373-383

(MHC) system, it has been suggested that narcolepsy may result from an autoimmune reaction to environmental agents (Lin et al. 2001).

Naturally occurring narcolepsy was first described in the dog in the 1970s (Knecht et al. 1973). Narcoleptic dogs have clinical signs that parallel those observed in humans and were used as a model to elucidate the genetics underlying the disorder (Hungs et al. 2006). In the dog, narcolepsy is inherited in an autosomal recessive fashion and, unlike the human, is not associated with the dog leukocyte antigen (DLA) system (Foutz et al. 1979; Wagner 2000). In 1999, colonies of Doberman pinchers and Labrador retrievers with narcolepsy were used in positional cloning efforts that identified linkage with the hypocretin/orexin receptor 2 (Hcrtr-2) gene (Lin et al. 1999). Hypocretin proteins (orexins), discovered in 1998, are neurotransmitters processed from a common precursor, preprohypocretin (Hcrt) (de Lecea et al. 1998; Sakurai et al. 1998). Independent mutations in these canine families cause exon-skipping and result in altered proteins. In addition, Hungs et al. (2006) identified a single-base change resulting in an amino acid substitution in Hcrtr-2 that causes narcolepsy in a family of Dachshunds. Hcrtr-2 does not cause narcolepsy in a family of poodles or in 11 individual cases with no family history (Hungs et al. 2006).

The role of hypocretins in canine narcolepsy, and the simultaneous finding that orexin knockout mice have narcoleptic symptoms (Chemelli et al. 1999), led to the investigation of hypocretins in humans. Hcrt and its receptors encoded by Hcrtr-1 and Hcrtr-2 were sequenced in human patients with narcolepsy and a substitution mutation in Hcrt of a single patient was identified (Peyron et al. 2000). Although mutations in these genes may be a rare cause of human narcolepsy, expression studies show 
that hypocretins are important in the etiology of the disorder. Hypocretin concentrations are below average or undetectable in the cerebrospinal fluid of most narcoleptic patients, indicating deficient neurotransmission (Nishino et al. 2000; Peyron et al. 2000).

Current treatments address only the symptoms of narcolepsy and have significant side effects (Nishino et al. 1997). The availability of a naturally occurring canine model has allowed pharmacologic studies to improve treatments for narcoleptic patients (Nishino et al. 1994). Animal models are currently being used to study the hypocretin system as a target for new therapeutic approaches (Dauvilliers and Tafti 2006). In addition, the canine models in which the causative factors remain unknown may still be useful for unmasking the genetic and environmental factors that are associated with narcolepsy.

\section{Retinal degeneration}

Retinitis pigmentosa (RP) is a group of hereditary disorders characterized by progressive retinal degeneration, eventual night blindness, loss of peripheral vision, and often complete blindness. RP affects 1 in 4000 people and may be inherited as an autosomal dominant, autosomal recessive, or X-linked trait (Hartong et al. 2006). More than 45 genes, accounting for $60 \%$ of all cases, have been implicated in RP (Hartong et al. 2006).

Progressive retinal atrophy (PRA) is a group of hereditary diseases of the dog that are phenotypically and molecularly similar to RP. Progressive rod-cone degeneration (prcd) is an autosomal recessive, late-onset form of PRA. In 1998, the prcd locus was mapped to the centromeric end of CFA9 using classical linkage analysis (Acland et al. 1998). Fortuitously, prcd in multiple breeds results from allelic or identical mutations in the $P R C D$ gene. This allowed for multiple breeds to be used in a large-scale linkage disequilibrium (LD) approach, which further defined the interval that harbors the prcd locus (Goldstein et al. 2006). A retinal EST library was instrumental in the identification of novel candidate genes in this region (Zangerl et al. 2006a, b). A single G-to-A transition in a gene of unknown function, termed $P R C D$, was found to cause prcd in at least 18 breeds (Zangerl et al. 2006b).

Upon discovery of the canine mutation, human patients with inherited retinal disorders for which known causative mutations had been excluded were screened for mutations in the PRCD gene. A woman from Bangladesh having an autosomal recessive form of RP was found to harbor a homozygous mutation in the $P R C D$ gene (Zangerl et al. 2006b). Interestingly, the mutation is identical at the genetic and protein level to the mutation causing prcd in the dog (Zangerl et al. 2006b).
Table 1 Mutations in canine hemophilia B

\begin{tabular}{lll}
\hline Breed & Mutation & Reference \\
\hline Not reported & Missense & $\begin{array}{c}\text { Evans et al. } \\
1989 \mathrm{~b}\end{array}$ \\
Lhaso Apso & Mauser et al. & 1996 \\
Labrador Retriever & Complete gene & Brooks et al. \\
& deletion & 1997 \\
American Pit Bull Terrier & Partial gene deletion & Gu et al. 1999 \\
mix & 5-kb insertion & Gu et al. 1999 \\
Airedale Terrier & LINE1 insertion & Brooks et al. \\
German Wirehair Pointer & & 2003 \\
\hline
\end{tabular}

Canine breed, mutation, and reference are shown for each of the six cases of hemophilia B in which the underlying genetics has been reported

The similarities between humans and dogs can be exploited to develop treatments for retinal degenerative diseases, with significant strides in this field having already been made. In 2001, gene therapy restored vision to dogs with severe retinal degeneration caused by a homozygous, 4-bp deletion in RPE65 (Acland et al. 2001). The dose efficacy and safety data obtained from the successful use of the canine model have led to gene therapy studies in nonhuman primates and the consideration of human trials (Jacobson et al. 2006).

\section{Hemophilia B}

Hemophilia B is a recessive bleeding disorder that results from mutations in the Factor IX (FIX) gene on the $\mathrm{X}$ chromosome. FIX, synthesized by hepatocytes, is an essential part of the blood coagulation cascade. Clotting factor deficiencies result in bleeding into joints, soft tissue, and muscles. Such bleeding may occur spontaneously or be triggered by a minor injury. Hemophilia B is estimated to occur in 1 in 30,000 males and is both clinically and molecularly heterogeneous. Approximately 1000 unique mutations causing hemophilia B have been reported in humans (Green et al. 2004).

Canine hemophilia B is highly similar to the human disease and is well studied. In 1989, Evans et al. (1989a) published the coding sequence of canine FIX. The same group also identified the first known mutation to cause hemophilia $\mathrm{B}$ in the dog, a missense mutation resulting in the complete absence of detectable protein (Evans et al. 1989b). Since then, multiple cases have been described in different breeds and distinct mutations for five of these have been reported (Table 1) (Brooks et al. 1997, 2003; Gu et al. 1999; Mauser et al. 1996).

The standard treatment for hemophilia B is intravenous infusion of FIX concentrates to prevent or treat bleeding 
episodes. While treatment is effective and generally safe, it is expensive and inconvenient (Lillicrap et al. 2006). Molecular therapies for hemophilia B are being investigated not only to provide patients with treatment options but also to evaluate the overall efficacy of such approaches. The factors that make hemophilia a superior model for assessment of genetic intervention strategies are (1) tissuespecific gene expression is not necessary, (2) nominal increases in clotting factor levels will result in significant phenotypic improvements, (3) measurement of clotting factor levels can be achieved through simple blood tests, and (4) naturally occurring canine models are available (Lillicrap et al. 2006).

A colony of dogs with hemophilia B due to a missense mutation first characterized by Evans et al. (1989b), has been used in numerous pioneering gene therapy studies (Kay et al. 1993, 1994; Snyder et al. 1999; Wang et al. 2000). The first of these utilized a retroviral vector containing FIX cDNA and resulted in long-term expression of low levels of FIX (Kay et al. 1993). A subsequent study used a recombinant adenoviral vector and achieved shortterm expression of therapeutic levels of FIX (Kay et al. 1994). To attain both long-term and therapeutic levels of FIX expression in these dogs, researchers found success by using adeno-associated viral (AAV) vectors (Herzog et al. 1999; Snyder et al. 1999; Wang et al. 2000). An AAV vector was also later used to correct a severe hemophilia $\mathrm{B}$ phenotype in dogs with a null mutation (Mount et al. 2002).

The data obtained using the AAV vector in these canine studies provided the proof of principle necessary to move forward with hemophilia B gene therapy trials in humans (High 2004). The dog has also been instrumental in advancing molecular therapy approaches for hemophilia A, which results from factor VIII deficiency (Lillicrap et al. 2006). Hemophilia A is significantly more common than hemophilia B, but gene therapy studies have been impeded by large size of the FVIII gene (Kay and High 1999).

\section{Muscular dystrophy}

The most common and severe muscular disorder in humans is Duchenne muscular dystrophy (DMD). DMD is an Xlinked disorder that results in muscle degeneration and death around the age of 20. It affects approximately 1 in 3500 males and there are currently no effective treatments available. A naturally occurring form of DMD has been described in the golden retriever (Kornegay et al. 1988). Golden retriever muscular dystrophy (GRMD) is characterized by elevated serum creatinine kinase activity, progressive muscle atrophy and necrosis, and regeneration by fibrotic and adipose tissues. Affected dogs develop clinical signs in 8-10 weeks (Kornegay et al. 1988).

DMD is caused by a defective dystrophin gene, which codes for a cytoskeletal protein responsible for stabilizing the sarcolemma (Hoffman et al. 1987). Northern and Western blots using human probes failed to detect dystrophin transcripts or proteins in muscle tissue from GRMDaffected dogs (Cooper et al. 1988). Sequence analysis of the dystrophin gene revealed an A-to-G transition in the exon 7 splice acceptor of affected dogs (Sharp et al. 1992). This mutation causes either the deletion of exon 7 or the use of an alternative splice site $5 \mathrm{bp}$ downstream; both result in a reading frame shift and a truncated transcript (Dell'Angola et al. 2004; Sharp et al. 1992).

The frequency and severity of DMD has fueled interest in the development of gene therapies for patients. Significant advancements have come from a murine model, but greater similarities in disease progression make the dog a more attractive model (Foster et al. 2006; Tanabe et al. 1986). Initial gene therapy studies in the dog focused on the dystrophin gene and were promising (Howell et al. 1997). An alternative approach involved upregulation of utrophin, a gene functionally and structurally similar to dystrophin, but not foreign to DMD patients (Cerletti et al. 2003). Delivery of mini-utrophin transcripts via an adenoviral vector mitigated the dystrophic phenotype in the muscles of GRMD dogs; however, slight immunologic reactions to the vector and transgene occurred (Cerletti et al. 2003). An additional method involved modified antisense oligonucleotides (AOs) that cause exon-skipping. By changing the splicing pattern, AOs can cause a mutated exon to be removed from the pre-mRNA, leading to a functional protein. McClorey et al. (2006) successfully used AOs to restore dystrophin expression in dogs.

Human gene therapy studies have been successful as well, with several types of vectors used to deliver dystrophin to dystrophic muscles. AAV vectors have been problematic because of their limited carrying capacity and the large size of the dystrophin gene. The use of microdystrophin (a truncated but functional version of the dystrophin gene) has shown promise and initial trials are underway (Foster et al. 2006). In addition, with the success of AO treatment in the dog, human phase 1 clinical trials have been initiated (Foster et al. 2006; http://www.muscular-dystrophy.org, http://www.ppuk.org).

In an effort to eliminate immune reactions against vectors and/or the dystrophin gene itself, researchers investigated the use of stem cells to treat GRMD. Hematopoetic stem cells have proven to be effective in muscle regeneration in the murine $m d x$ model (Gussoni et al. 1999). Unfortunately, hematopoetic stem cells from normal littermates did not cause muscle regeneration in affected dogs (Dell'Angola et al. 2004). Vessel-associated stem cells, 
called mesoangioblasts, were also studied. Mesoangioblasts were successfully transplanted and expressed dystrophin, allowing recovery of muscle use (Sampaolesi et al. 2006). Donor wild-type mesoangioblasts were found to be more effective than genetically corrected autologous mesoangioblast cells (Sampaolesi et al. 2006). All dogs treated with wild-type cells displayed initial mobility improvements and one dog was still walking five months after cessation of treatments (Sampaolesi et al. 2006).

\section{Summary}

Presented here are examples of studies that were critical to identification and treatment of genetically simple diseases that affect the human and dog. However, the genetics of complex diseases are more difficult to assess-in the dog and human. Nevertheless, with new genomic tools/resources now available for study of the dog, workers have now begun analyses of complex diseases such as cancers, cardiovascular diseases (e.g., cardiomyopathy), and neurologic diseases (e.g., epilepsy). In addition, the dog is being used to assess the genetics of morphologic development and behavior due to the unique physical and behavioral traits that characterize individual breeds. The hypothesis for such lines of investigation is simple: while there likely are additional factors that influence behavior, morphology, and progression of diseases in the dog and human, the major genes influencing these may very well be the same.

One complex disease for which data are available from the dog is canine hip dysplasia (CHD) or degenerative joint disease, the major orthopedic disease of the dog. This is a painful and crippling disease that has a counterpart in the human termed developmental dislocation of the hip. Researchers are exploiting the natural occurrence of CHD in both pet populations and designed outcrossed pedigrees in an attempt to delimit contributory genetic components to this disease (Chase et al. 2004; Todhunter et al. 1999; Tsai and Murphy 2006). To date, two QTLs have been identified in the Portuguese water dog (PWD) on CFA01 that are associated with joint laxity as measured by the Norberg angle. Interestingly, one of the QTLs is associated with joint laxity in the right hip while the other is associated with the left hip (Chase et al. 2004). The same PWD population was used recently to identify the insulin-like growth factor 1 gene $(I G F 1)$ as a determinant for skeletal size in dogs (Sutter et al. 2007). This is an important finding because understanding the genetics of growth and regulation may provide insight into complex diseases such as cancer and hip dysplasia.

The diseases discussed in this article highlight the importance of the dog to biomedical research, particularly the study of hereditary diseases. Perhaps most unique about the use of the $\operatorname{dog}$ as a model is this: study of those hereditary diseases common to the dog and human allows both to benefit as opposed to one serving merely as a model for the other. A paucity of genetic tools with which to study the canine genome previously prohibited researchers from exploiting the canine model. Thus, the majority of research in the dog was guided by our knowledge of the disease in the human. With the necessary resources now available, discoveries in the dog are being used to define causative genes and pathways and, importantly, develop new treatment regimens for the human.

Acknowledgment The authors thank Dr. George Lees of Texas A\&M University for Figure 1.

\section{References}

Acland GM, Ray K, Mellersh CS, Gu W, Langston AA, et al. (1998) Linkage analysis and comparative mapping of canine progressive rod-cone degeneration ( $p r c d$ ) establishes potential locus homology with retinitis pigmentosa (RP17) in humans. Proc Natl Acad Sci U S A 95:3048-3053

Acland GM, Aguirre GD, Ray J, Zhang Q, Aleman TS, et al. (2001) Gene therapy restores vision in a canine model of childhood blindness. Nat Genet 28:92-95

Breen M, Hitte C, Lorentzen TD, Thomas R, Cadieu E, et al. (2004) An integrated 4249 marker FISH/RH map of the canine genome. BMC Genomics 5:65-75

Brooks MB, Gu W, Ray K (1997) Complete deletion of factor IX gene and inhibition of factor IX activity in a labrador retriever with hemophilia B. J Am Vet Med Assoc 211:1418-1421

Brooks MB, Gu W, Barnas JL, Ray J, Ray K (2003) A line 1 insertion in the factor IX gene segregates with mild hemophilia in dogs. Mamm Genome 14:788-795

Cerletti M, Negri T, Cozzi F, Colpo R, Andreetta F, et al. (2003) Dystrophic phenotype of canine X-linked muscular dystrophy is mitigated by adenovirus-mediated utrophin gene transfer. Gene Ther 10:750-757

Chase K, Lawler DF, Adler FR, Ostrander EA, Lark KG (2004) Bilaterally asymmetric effects of quantitative trait loci (QTLs): QTLs that affect laxity in the right versus left coxofemoral (hip) joints of the dog (Canis familiaris). Am J Med Genet 124A:239247

Chemelli RM, Willie JT, Sinton CM, Elmquist JK, Scammell T, et al. (1999) Narcolepsy in orexin knockout mice: Molecular genetics of sleep regulation. Cell 98:437-451

Clark LA, Wahl JM, Steiner JM, Zhou W, Ji W, et al. (2005) Linkage analysis and gene expression profile of pancreatic acinar atrophy in the German Shepherd Dog. Mamm Genome 16:955-962

Cooper BJ, Winand NJ, Stedman H, Valentine VA, Hoffman EP, et al. (1988) The homologue of the Duchenne locus is defective in X-linked muscular dystrophy of dogs. Nature 334:154-156

Cosgrove D, Meehan DT, Grunkemeyer JA, Kornak JM, Sayers R, et al. (1996) Collagen COL4A3 knockout: a mouse model for autosomal Alport syndrome. Genes Dev 10:2981-2992

Cox ML, Lees GE, Kashtan CE, Murphy KE (2003) Genetic cause of $\mathrm{X}$-linked Alport syndrome in a family of domestic dogs. Mamm Genome 14:396-403

Dauvilliers Y, Tafti M (2006) Molecular genetics and treatment of narcolepsy. Ann Med 38:252-262 
Dauvilliers Y, Billiard M, Montplaisir J (2003) Clinical aspects and pathophysiology of narcolepsy. Clin Neurophysiol 114:20002017

Davidson AG, Bell RJ, Lee GE, Kashtan CE, Davidson GS, Murphy KE (2007) Genetic cause of autosomal recessive hereditary nephropathy in the English cocker spaniel. J Vet Intern Med 21:394-401

de Lecea L, Kilduff TS, Peyron C, Gao X, Foye PE, et al. (1998) The hypocretins: hypothalamus-specific peptides with neuroexcitatory activity. Proc Natl Acad Sci U S A 95:322-327

Dell'Angola C, Wang Z, Storb R, Tapscott SJ, Kuher CS, et al. (2004) Hematopoietic stem cell transplantation does not restore dystrophin expression in Duchenne muscular dystrophy dogs. Blood 104:4311-4318

Evans JP, Watzke HH, Ware JL, Stafford DW, High KA (1989a) Molecular cloning of a cDNA encoding canine factor IX. Blood 74:207-212

Evans JP, Brinkhous KM, Brayer GD, Reisner HM, High KA (1989b) Canine hemophilia $\mathrm{B}$ resulting from a point mutation with unusual consequences. Proc Natl Acad Sci U S A 86:1009510099

Foster K, Foster H, Dickson JG (2006) Gene therapy progress and prospects: Duchenne muscular dystrophy. Gene Ther 13:16771685

Foutz AS, Mitler MM, Cavalli-Sforza LL, Dement WC (1979) Genetic factors in canine narcolepsy. Sleep 1:413-421

Goldstein O, Zangerl B, Pearce-Kelling SE, Sidjanin DJ, Kijas JW, et al. (2006) Linkage disequilibrium mapping in domestic dog breeds narrows the progressive rod-cone degeneration interval and identifies ancestral disease-transmitting chromosome. Genomics 88:541-550

Green PM, Giannelli F, Sommer SS, Poon M-C, Ludwig M, et al. (2004) The haemophilia B mutation database, ver. 13. Available at http://www.kcl.ac.uk/ip/petergreen/intro.html

Gu W, Brooks M, Catalfamo J, Ray J, Ray K (1999) Two distinct mutations cause severe hemophilia $\mathrm{B}$ in two unrelated canine pedigrees. Thromb Haemost 82:1270-1275

Gussoni E, Soneoka Y, Strickland CD, Buzney EA, Khan MK, et al. (1999) Dystrophin expression in the mdx mouse restored by stem cell transplantation. Nature 401:390-394

Guyon R, Lorentzen TD, Hitte C, Kim L, Cadieu E, et al. (2003) A 1$\mathrm{Mb}$ resolution radiation hybrid map of the canine genome. Proc Natl Acad Sci U S A 100:5296-5301

Hartong DT, Berson EI, Dryja TP (2006) Retinitis pigmentosa. Lancet 368:1795-1809

Harvey SJ, Zheng K, Jefferson B, Moak P, Sado Y, et al. (2003) Transfer of the $\alpha 5$ (IV) collagen chain gene to smooth muscle restores in vivo expression of the $\alpha 6$ (IV) collagen chain in a canine model of Alport syndrome. Am J Pathol 162:873-885

Heikkilä P, Tibell A, Morita T, Chen Y, Wu G, et al. (2001) Adenovirus-mediated transfer of type IV collagen $\alpha 5$ chain cDNA into swine kidney in vivo: deposition of the protein into the glomerular basement membrane. Gene Ther 8:882-890

Herzog RW, Yang EY, Couto LB, Hagstrom JN, Elwell D, et al. (1999) Long-term correction of canine hemophilia B by gene transfer of blood coagulation factor IX mediated by adenoassociated viral vector. Nat Med 5:56-63

High KA (2004) Clinical gene transfer studies for hemophilia B. Semin Thromb Hemost 30:257-267

Hoffman EP, Brown RH Jr, Kunkel LM (1987) Dystrophin: the protein product of the Duchenne muscular dystrophy locus. Cell 51:919-928

Hood JC, Savige J, Hendtlass A, Kleppel MM, Huxtable CR, et al. (1995) Bull terrier hereditary nephritits: a model for autosomal dominant Alport syndrome. Kidney Int 47:758-765
Howell JM, Fletcher S, Kakulas BA, O'Hara M, Lochmuller H, et al. (1997) Use of the dog model for Duchenne muscular dystrophy in gene therapy. Neuromuscul Disord 7:325-328

Hudson BG, Tryggvason K, Sundaramoorthy M, Neilson EG (2003) Alport's syndrome, Goodpasture's syndrome, and type IV collagen. N Engl J Med 348:2543-2556

Hungs M, Fan J, Lin L, Lin X, Maki R, et al. (2006) Identification and functional analysis of mutations in the hypocretin (orexin) genes of narcoleptic canines. Gen Res 11:531-539

Jacobson SG, Boye SL, Aleman TS, Conlon TJ, Zeiss CJ, et al. (2006) Safety in nonhuman primates of ocular AAV2-RPE65, a candidate treatment for blindness in Leber congenital amaurosis. Hum Gene Ther 17:845-858

Jais JP, Knebelmann B, Giatras I, de Marchi M, Rizzoni G, et al. (2000) X-linked Alport syndrome: Natural history in 195 families and genotype-phenotype correlations in males. J Am Soc Nephrol 11:649-657

Jansen B, Thorner P, Baumal R, Valli V, Maxie MG, et al. (1986) Samoyed hereditary glomerulopathy (SHG). Evolution of splitting of glomerular capillary basement membranes. Am J Pathol 125:536-545

Juji T, Satake M, Honda Y, Doi Y (1984) HLA antigens in Japanese patients with narcolepsy. Tissue Antigen 24:316-319

Kashtan CE (1998) Disease of the month: Alport syndrome and thin glomerular basement membrane disease. J Am Soc Nephrol 9:1736-1750

Kashtan CE (2002) Animal models of Alport syndrome. Nephrol Dial Transplant 17:1359-1361

Kay MA, High K (1999) Gene therapy for the hemophilias. Proc Natl Acad Sci U S A 96:9973-9975

Kay MA, Rothenburg S, Landen CN, Bellinger DA, Leland F, et al. (1993) In vivo gene therapy of hemophilia B: sustained partial correction in factor IX-deficient dogs. Science 262:117-119

Kay MA, Landen CN, Rothenberg SR, Taylor LA, Leland F, et al. (1994) In vivo hepatic gene therapy: complete albeit transient correction of factor IX deficiency in hemophilia B dogs. Proc Natl Acad Sci U S A 91:2353-2357

Knebelmann B, Forestier L, Drouot L, Quinones S, Chuet C, et al. (1995) Splice-mediated insertion of an Alu sequence in the COL4A3 mRNA causing autosomal recessive Alport syndrome. Hum Mol Genet 4:675-679

Knecht CD, Oliver JE, Redding R, Selcer R, Johnson G (1973) Narcolepsy in a dog and a cat. J Am Vet Med Assoc 162:10521053

Kornegay JN, Tuler SM, Miller DM, Levesque DC (1988) Muscular dystrophy in a litter of golden retriever dogs. Muscle Nerve 11:1056-1064

Lees GE, Helman RG, Kashtan CE, Michael AF, Homco LD, et al. (1999) New form of X-linked dominant hereditary nephritis in dogs. Am J Vet Res 60:373-383

Lemmink HH, Mochizuki T, van den Heuvel LPWJ, Schroder CH, Barrientos A, et al. (1994) Mutations in the type IV collagen $\alpha 3$ (COL4A3) gene in autosomal recessive Alport syndrome. Hum Mol Genet 3:1269-1273

Lillicrap D, Vandenriessche T, High K (2006) Cellular and genetic therapies for haemophilia. Haemophilia 12:36-41

Lin L, Faraco J, Li R, Kadotani H, Rogers W, et al. (1999) The sleep disorder canine narcolepsy is caused by a mutation in the hypocretin (orexin) receptor 2 gene. Cell 98:365-376

Lin L, Hungs M, Mignot E (2001) Narcolepsy and the HLA region. J Neuroimmunol 117:9-20

Lindblad-Toh K (2006) Trait mapping using a canine SNP array. In Proceedings of the 3rd International Conference on Advances in Canine and Feline Genomics. Davis, CA, 2-5 August 2006 
Lindblad-Toh K, Wade CM, Mikkelsen TS, Karlsson EK, Jaffe DB, et al. (2005) Genome sequence, comparative analysis and haplotype structure of the domestic dog. Nature 438:803-819

Maret S, Tafti M (2005) Genetics of narcolepsy and other major sleep disorders. Swiss Med Wkly 135:662-665

Martin P, Heiskari N, Zhou J, Leinonen A, Tumelius T, et al. (1998) High mutation detection rate in the COLAA5 collagen gene in suspected Alport syndrome using PCR and direct DNA sequencing. J Am Soc Nephrol 9:2291-2301

Mauser AE, Whitlark J, Whitney KM, Lothrop CD (1996) A deletion mutation causes hemophilia B in Lhasa Apso dogs. Blood 88:3451-3455

McClorey G, Moulton HM, Iversen PL, Fletcher S, Wilton SD (2006) Antisense oligonucleotide-induced exon skipping restores dystrophin expression in vitro in a canine model of DMD. Gene Ther 13:1373-1381

Mignot E (1998) Genetic and familial aspects of narcolepsy. Neurol 50(Suppl 1):S16-S22

Mignot E (2004) Sleep, sleep disorders and hypocretin (orexin). Sleep Med 5(Suppl 1):S2-S8

Miner JH, Sanes JR (1996) Molecular and functional defects in kidneys of mice lacking collagen $\alpha 3$ (IV): Implications for Alport syndrome. J Cell Biol 135:1403-1413

Mochizuki T, Lemmink HH, Mariyama M, Antignas C, Gubler MC, et al. (1994) Identification of mutations in the alpha-3(IV) and alpha-4(IV) collagen genes in autosomal recessive Alport syndrome. Nat Genet 8:77-82

Mount JD, Herzog RW, Tillson DM, Goodman SA, Robinson N, et al. (2002) Sustained phenotypic correction of hemophilia B dogs with a factor IX null mutation by liver-directed gene therapy. Blood 99:2670-2676

Nishino S, Arrigoni J, Shelton J, Kanbayashi T, Dement WC, Mignot E (1997) Affects of thyrotropin-releasing hormone and its analogs on daytime sleepiness and cataplexy in canine narcolepsy. J Neurosci 17:6401-6408

Nishino S, Reid MS, Dement WC, Mignot E (1994) Neuropharmacology and neurochemistry of canine narcolepsy. Sleep 17:S84S92

Nishino S, Ripley B, Overeem S, Lammers GJ, Mignot E (2000) Hypocretin (orexin) deficiency in human narcolepsy. Lancet 355:39-40

Online Mendelian Inheritance in Animals, OMIA. Reprogen, Faculty of Veterinary Science, University of Sydney and Australian National Genomic Information Service (ANGIS), University of Sydney, January 2007. Available at: http://www.omia.angis.org.au/

Ostrander EA, Giniger E (1997) Semper fidelis: What man's best friend can teach us about human biology and disease. Am J Hum Genet 61:475-80

Ostrander EA, Galibert F, Patterson DF (2000) Canine genetics comes of age. Trends Genet 16:117-124

Peyron C, Faraco J, Rogers W, Ripley B, Overeem S, et al. (2000) A mutation in a case of early onset narcolepsy and a generalized absence of hypocretin peptides in human narcoleptic brains. Nat Med 6:991-997
Rheault MN, Kren SM, Thielen BK, Mesa HA, Crosson JT, et al. (2004) Mouse model of X-linked Alport Syndrome. J Am Soc Nephrol 15:1466-1474

Sakurai T, Amemiya A, Ishii M, Matsuzaki I, Chemelli RM, et al. (1998) Orexins and orexin receptors: a family of hypothalamic neuropeptides and $\mathrm{G}$ protein-coupled receptors that regulate feeding behavior. Cell 92:573-585

Sampaolesi M, Blot S, D'Antona G, Granger N, Tonlorenzi R, et al. (2006) Mesoangioblast stem cells ameliorate muscle function in dystrophic dogs. Nature 444:574-579

Seignalet J, Billiard M (1984) Possible association between HLA-B7 in narcolepsy. Tissue Antigens 23:188-189

Sharp NJH, Kornegay JN, Van Camp SD, Herbstrieth MH, Secore SL, et al. (1992) An error in dystrophin mRNA processing in golden retriever muscular dystrophy, an animal homologue of Duchenne muscular dystrophy. Genomics 13:115-121

Snyder RO, Miao C, Meuse L, Tubb J, Donahue BA, et al. (1999) Correction of hemophilia B in canine and murine models using recombinant adeno-associated viral vectors. Nat Med 5:64-70

Sutter NB, Bustamante CD, Chase K, Gray MM, Zhao K, et al. (2007) A single $I G F 1$ allele is a major determinant of small size in dogs. Science 316:112-115

Tanabe Y, Esaki K, Nomura T (1986) Skeletal muscle pathology in X chromosome-linked muscular dystrophy $(\mathrm{mdx})$ mouse. Acta Neuropathol (Berl) 69:91-95

Todhunter RJ, Acland GM, Olivier M, Williams AJ, Vernier-Singer M, et al. (1999) An outcrossed canine pedigree for linkage analysis of hip dysplasia. J Hered 90:83-92

Tsai KL, Murphy KE (2006) clinical and genetic assessments of hip joint laxity in the Boykin Spaniel. Can J Vet Res 70:148-150

Tryggvason K, Martin P (2001) Alport syndrome and basement membrane collagen. In: The Metabolic and Molecular Basis of Inherited Disease, Schriver CR, Beaudet AL, Sly WS, Valle D, Childs B, et al. (eds.) (Philadelphia: McGraw-Hill), chap 214, pp 5453-5466

Wagner JL, Storb R, Storer B, Mignot E (2000) DLA-DQB1 alleles and bone marrow transplantation experiments in narcoleptic dogs. Tissue Antigens 56:223-231

Wang L, Nichols TC, Read MS, Bellinger DA, Verma IM (2000) Sustained expression of therapeutic level of factor IX in hemophilia B dogs by AAV-mediated gene therapy in liver. Mol Ther 1:154-158

Zangerl B, Sun Q, Pillardy J, Johnson JL, Schweitzer PA, et al. (2006a) Development and characterization of a normalized canine retinal cDNA library for genomic and expression studies. Invest Opthalmol Vis Sci 47:2632-2638

Zangerl B, Goldstein O, Philp AR, Lindauer SJP, Pearce-Kelling SE, et al. (2006b) Identical mutation in a novel retinal gene causes progressive rod-cone degeneration in dogs and retinitis pigmentosa in humans. Genomics 88:551-563

Zheng K, Thorner PS, Marrano P, Baumal R, McInnes RR (1994) Canine X chromosome-linked hereditary nephritis: A genetic model for human $\mathrm{X}$-linked hereditary nephritis resulting from a single base mutation in the gene encoding the $\alpha 5$ chain of collagen type IV. Proc Natl Acad Sci U S A 91:3989-3993 